\title{
Juicio oral: los entuertos del Quijote en la versión quechua
}

\section{Oral Judgment: Don Quijote's Nonsenses on the Quechua Version}

\section{Odi Gonzales ${ }^{1}$}

Center for Latin American and Caribbean Studies, Department of Spanish and Portuguese, New York University, Nueva York

\section{RESUMEN}

La reciente noticia de la traducción de la segunda parte del Quijote al quechua -la lengua nativa más extendida de los Andes - ha motivado una legítima expectativa en el Perú, en Latinoamérica y en España, donde se celebra el cuarto centenario de su publicación (1615). Sin embargo, una cuidadosa lectura de la versión quechua de la portentosa novela de Cervantes (primera parte), alberga imprecisiones y arbitrariedades que acechan desde el título. El presente trabajo analiza la traducción de Demetrio Túpac Yupanqui, que entremezcla dos códigos irreductibles forzando la naturaleza oral de la lengua quechua en el discurso escrito de una novela, lo que la hace, por momentos, ininteligible para los lectores quechuahablantes.

\section{PALABRAS CLAVE}

El Quijote quechua, oralidad y escritura quechua, traducción-yuxtaposición, Demetrio Túpac Yupanqui

\section{ABSTRACT}

The recent news of the translation of the second part of don Quijote to Quechua — the most widely spoken

1 Doctor en Literatura Peruana y Latinoamericana. Odi Gonzales es estudioso de la tradición oral quechua, poeta, traductor y profesor universitario en el Perú y Estados Unidos. En 1992, mereció el Premio Nacional de Poesía César Vallejo y el Premio de Poesía de la Universidad Nacional Mayor de San Marcos de Lima. Ha publicado los libros de poesía Juego de niños (1989), Valle sagrado (1993), Almas en pena (1998), Tunupa. El libro de las sirenas (2002), La escuela de Cusco (2005), Valle sagrado. Almas en pena (2008, segunda edición), Avenida sol. Greenwich Village (2009). Asimismo, tiene los libros de investigación El condenado o alma en pena en la tradición oral andina (1995), Takiparwa, 22 poemas quechuas de KilkuWarak'a (2000), Elegía Apu Inka Atawallpaman. Primer documento de la resistencia inka (siglo XVI) (2014). Traducido al inglés por la poeta norteamericana Lynn Levin, el libro de poesía La Escuela de Cusco. Birds on the Kiswar Tree acaba de salir en Nueva York (2Leaf Press). Desde 2008 es profesor del Programa de Quechua y Literaturas Prehispánicas de New York University. 
indigenous language in the Andean region - has raised great expectations in Peru, Latin America and Spain, countries that are celebrating the 400th year anniversary of the book's publication (part two, 1615). However a careful reading of the Quechua version of Cervantes' novel (part one), contains inaccuracies and arbitrariness that begin from the very title. This article analyze the translation of Demetrio Tupac Yupanqui that intersperses two incompatible codes, forcing the oral nature of Quechua language into writing discourse of a novel, which make it illegible for Quechua speaker readers.

\section{KEYWORDS}

Quijote Quechua, oral and writing codes, translationapposition, Demetrio Tupac Yupanqui

\section{Material noble}

El hecho de que el runasimi o quechua pueda fijarse en la escritura con caracteres del español no significa que la ancestral lengua nativa de los Andes haya perdido su índole oral y devenido en lengua escrita. Ni siquiera la lengua maya, que alcanzó a configurar un sistema de escritura a través de glifos o logogramas, abdicó de su naturaleza oral. Las estrategias narrativas de las lenguas orale ${ }^{2}$ conciben relatos breves, concisos, memorizables, con un ordenamiento espacio-temporal, con encabalgamientos de sucesos distintos al de la estructura narrativa de una novela o de un cuento (escrito).

En la urdimbre del discurso literario gravita un léxico de abstracciones y conceptos que no es usual en el quechua, que es, más bien, proclive a las acciones concretas. «Libros» emblemáticos de la oralidad quechua como Dioses y hombres de Huarochirí (siglo XVI) o Autobiografía de Gregorio Condori y Asunta Mamani (siglo XX), no obstante su extensión de muchos segmentos - que no son capítulos- y las asociaciones entre el inicio y el fin, no son novelas: son un conjunto de minuciosas, sucintas y autónomas narraciones orales, ajenas a una organización y estructura novelística. Por esta razón, en principio, la versión quechua

2 El monólogo interior diestramente desarrollado por Joyce en Ulises (1922), y ponderado desde entonces como una técnica literaria, es inherente a las lenguas orales. En el quechua, el pronombre ñoqayku (nosotros exclusivo) que atañe al hablante y su entorno más próximo es la primera instancia del monólogo interior. La confluencia de ciertos sufijos direccionales (por ejemplo. el regresivo -pu con el reflexivo -ku) denotan que el narrador eventualmente habla para sí mismo (rimapakuy). Una diferencia básica con el monólogo interior de la novelística es la brevedad. El monólogo de Molly Bloom abarca cerca de 40 páginas. 


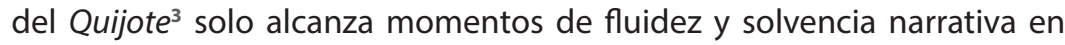
algunos pasajes, no en un capítulo completo y menos en la totalidad de la obra.

La aparición de la primera parte del Quijote en quechua (2005) y el reciente anuncio de la culminación de la segunda parte es una gesta muy peculiar. No se tiene conocimiento de ninguna otra lengua nativa -al menos de esta parte del continente- que haya emprendido tarea de tal magnitud. Que se sepa, no hay una versión del Quijote en guaraní, en maya-quiché, en zapoteco, en navajo, o en mapudungun, lo que hace loable la audacia del educador cusqueño Demetrio Túpac Yupanqui ${ }^{4}$, traductor del clásico cervantino.

\section{Flujo continuo}

En la tradición biobibliográfica peruana son pocas las experiencias de doblaje de textos del español al quechua. Lo que abunda hoy — gracias al impulso de las ciencias sociales y los estudios culturales- son los testimonios y los relatos orales quechuas recopilados in situ, transcritos, traducidos al español y publicados en ediciones bilingües ${ }^{5}$. Los primeros documentos evangelizadores son, sin duda, los antecedentes de esta modalidad. Doctrina christiana y Catecismo para instrucción de los indios, publicada en Lima en 1583, en el fragor de la evangelización, prefijó la traducción de breviarios, homilías, confesionarios y sermones del dogma cristiano «en las dos lenguas generales de este reyno, Quichua y Aymara» ${ }^{6}$. Años más tarde, a finales del siglo XIX, Clorinda Matto de Turner, la vigorosa autora de Aves sin nido, será quien traduzca pasajes de la Biblia -Pentateuco, libro de Job, Cantar de los Cantares, entre otros- al quechua. Contemporáneamente, esta práctica fue tornándose en abundancia banal con la aparición de pueriles doblajes que van desde los poemas de Vallejo hasta los anuncios del menú de restaurantes, folletos turísticos y una página en Google y Wikipedia en quechua, que discurren impunemente. Hay también una versión en runasimi de la Constitución del Perú elaborada —según los prolegómenos de este Quijote- por el propio Túpac Yupanqui.

3 Yachay sapa wiraqucha dun Quixote manchamantan Miguel de Cervantes Saavedra qilqan. Traducción y adaptación de Demetrio Túpac Yupanqui. Primera parte. Lima: El Comercio.

4 De niño, durante el gobierno de la Junta Militar del general Juan Velasco Alvarado (19681975) — que promovió resueltamente la revaloración y difusión del idioma quechua- solía oír a Yupanqui leyendo noticias y editoriales en quechua en radio y televisión. Otras veces escribía en las páginas de la edición quechua de La Crónica u otro periódico confiscado y puesto al servicio del Gobierno Revolucionario. Andando el tiempo, Yupanqui se estableció en Lima y fundó un centro de enseñanza del idioma quechua.

5 Colecciones de la Biblioteca de Tradición Oral Andina del Centro Bartolomé de las Casas de Cusco, del Instituto Francés de Estudios Andinos, del Instituto de Estudios Peruanos, entre otros, conforman esta vasta bibliografía.

6 La edición facsimilar fue promovida por Petroperú (Lima, 1992). 
Y de esta eclosión surgieron también el Himno Nacional del Perú ${ }^{7}$, y hasta los estatutos de creación de la Academia Mayor de la Lengua Quechua de Cusco $^{8}$, en la que los académicos osaron configurar equivalentes de una jerga jurídica ajena al quechua: «comuníquese y archívese», «artículos primero al tercero», «considerando», «por cuanto», «segundo secretario de la presidencia de la Cámara de Senadores» ${ }^{9}$, etc.

\section{Del título y otros entuertos}

Ilustrado con dibujos de la Asociación de Artistas Populares de Sarhua, El ingenioso hidalgo don Quixote de la Mancha, compuesto por Miguel de Cervantes Saavedra —título cabal de la primigenia edición de 1605, que Túpac Yupanqui toma como base - lleva la siguiente traducción en quechua sureño: Yachay Sapa Wiraqucha Dun Quixote Manchamantan Miguel de Cervantes Saavedra Qilqan, lo que traducido al español es: «El ingenioso hidalgo Don Quixote de la Mancha. Miguel de Cervantes Saavedra escribe».

Esta equivalencia, doblegada a la estructura castellana, entraña un agregado: la soterrada concurrencia de otra voz en la portada: la del traductor. Así, en el espacio consagrado al título de la obra y al nombre del autor, se acomoda furtivamente una voz extra, advenediza, que no traduce, que comenta que alguien (Cervantes) escribe (el Quijote). De esta manera se perpetra el primer forzamiento del quechua al intentar calcar el título castellano a la lengua traducida, siguiendo exactamente el ordenamiento estructural del español. Aunque en el libro se nos advierte que se trata de una «traducción y adaptación al quechua», lo evidente es que el quechua es sometido a la cadencia del español. En la construcción del antropónimo compuesto «Quixote Manchamantan» convergen el topónimo Mancha y el ablativo -manta, que marca el circunstancial de origen y procedencia (equivale a la preposición de). Esta traducción — tal como la vertió Yupanqui- sigue el esquema del sintagma nominal en español: el sustantivo Quixote resulta siendo el modificador y Manchamantan, el núcleo. Pero en la estructura del quechua el modificador (o adjetivo) precede

7 Barreto Ascarza, Ántero Jesús. (s. f.). Yachaywata yuyaque p'unchaykuna. Calendario cívico escolar. Cusco: Municipalidad del Cusco y Cervesur.

8 El documento de creación de esta institución apareció publicado en el Diario Oficial El Peruano (20 de junio 1990), de donde fue traducido al quechua por Melquíades Manga. El profesor Uriel Montufar, poeta y Miembro de Número de dicha Academia, lo insertó en su libro Takiyninchis. Poemas quechuas/castellanos (Arequipa, 1992).

9 El Acta de Independencia de Argentina fue difundida en 1816 en quechua y aimara. La breve versión «parafrásica» redactada en la variante quichua del noroeste argentino es notablemente legible, acaso porque el traductor (José Mariano Serrano, diputado por Charcas y oriundo de Chuquisaca, Bolivia) se centró únicamente en el meollo del acta, prescindiendo de los prolegómenos y colofones retórico-formales, y dejó tal cual vocablos que no tienen equivalentes en el quechua: congreso, jurar, rey de España, etc. 
al sustantivo (núcleo) ${ }^{10}$, lo que debería ser: Manchamantan Quixote ${ }^{11}$. Por otro lado, si optáramos por leer aplicando la otra función de mantan ${ }^{12}$, que no refiere procedencia sino alusión, la construcción quechua sometida al esquema castellano Quixote Manchamantan genera igualmente otra irresolución: el sufijo -manta equivale también a las preposiciones acerca de, sobre, de, una forma recurrente de los relatos orales para aludir a los personajes o hechos centrales o protagónicos de una historia; por ejemplo, Atoqmanta: “Acerca del zorro» ${ }^{13}$. Con esta acepción el término Manchamanta equivale a «Acerca de la Mancha» y la locución Quixote Manchamantan sería "Acerca de la Mancha Quixote» ${ }^{14}$. Curiosamente, la alusión manta era un recurso común de las crónicas, relaciones y obras literarias del siglo XVI, que a la manera de apostillas o sumillas abrían cada capítulo. Por ejemplo, el capítulo XI del Quijote va precedido por la siguiente nota: «De lo que sucedió a Don Quijote con unos cabreros», que Yupanqui resuelve con manta: "Dun Quijoteh kabra michihkunawan kasqanmanta» ${ }^{15}$. La memoria oral quechua no adjudica títulos a sus relatos; los refiere con esta modalidad; acaso un remanente del influjo de la escritura sobre la oralidad. Con todo, una traducción más coherente, aprehensible por los quechuahablantes, habría sido: Manchamanta Yachaysapa Wiraqucha Dun Quixote.

No viene al caso debatir sobre el equivalente ingenioso/yachay sapa ni hidalgo/wiraqucha, porque no transige con aspectos morfológicos, sino con preferencias para optar por las analogías más convenientes. El hecho de que el traductor haya trocado el predicado castellano don por dun, basado en la dicción española de un monolingüe quechua, consuma una doble transgresión del vocablo castellano a nivel escritural y oral ${ }^{16}$. Se violenta la lengua de Cervantes por fidelidad a la pronunciación del

10 El quechua comparte con el inglés este tipo de ordenamiento estructural; se dice white house, no al revés.

11 Eso mismo hace Yupanqui en la dedicatoria: «Al Duque de Béjar, Marqués de Gibraleón»: Gibraleonmanta marqués.

12 En el término Manchamantan la n final no cumple ninguna función gramatical; es solo énfasis.

13 Hay abundantes ejemplos de este uso que ha terminado por convertirse en el título de los relatos orales: Ararankamanta / Del lagarto, Chimaychero maqtakunamanta / De los mozos jaranistas (Arguedas 1986); Miguel Wayapamanta / Historia de Miguel Wayapa, Saqra michimanta (Lira 1990); Huk chiku mana mikhusqanmanta (Payne 1984).

14 En el caso del ejemplo del zorro, si este tuviera un nombre la construcción sería Jacinto Atoqmanta / Acerca del zorro Jacinto, donde el núcleo es Atoqmanta y el modificador, Jacinto. En Quixote Manchamanta el núcleo, calcado del esquema castellano, es Manchamanta («acerca de la Mancha») y el modificador, Quixote. Una última viabilidad es considerar Quixote como nombre y Mancha como apellido, pero ese no es el caso.

15 La transcripción Quixote de la portada es reemplazada por Quijote a lo largo de la novela. 16 Con este criterio pudo haber vertido también Quixuti. Yupanqui opta por la escritura trivocálica (a, i, u), basada en la dicción del monolingüe quechua. 
monolingüe, y se descarta la dicción de los mestizos quechuahablantes como si no formara parte de este proceso ${ }^{17}$. Según esto, los bilingües debemos leer, pronunciar y escribir «kawallu, liwru, diyus» en lugar de «caballo, libro, dios». Se respeta la pronunciación trivocálica del monolingüe, pero se violenta su estructura sintagmática. Más que una consideración a la pronunciación del hablante nativo, parece una pulsión invasiva en el que el mestizo bilingüe -incluido el traductor - debe simular la dicción del monolingüe acallando la suya propia ${ }^{18}$. Con esta praxis excluyente un hispanohablante tendrá que remodular la pronunciación de palabras de su propia lengua ${ }^{19}$. En el poema «Tupaq Amaru kamaq Taytanchisman» de Arguedas aparece el término cawallu, pero el maestro alcanzó a vislumbrar el problema 50 años atrás: «Es posible que los quechuólogos puristas se resientan al encontrar en el texto palabras castellanas con desinencias quechuas y algunos términos castellanos escritos tal como lo pronuncian los indios y mestizos» (Arguedas, 1984, pp. 59-60).

En cuanto a la traducción de la autoría, el segmento Miguel de Cervantes Saavedra Qilqan / Miguel de Cervantes Saavedra escribe culmina el cometido: la omnisciente voz del traductor invisibiliza al autor y le prodiga un comentario: Cervantes escribe El ingenioso Quijote de la Mancha. De hecho, con la intromisión de esta voz, el traductor termina desplazando al autor, de manera que Cervantes y el entrañable Caballero de la Triste Figura pasan a un segundo plano porque la voz del traductor lo dispone así. Con esto, Yupanqui superpone una metanarrativa escritural a una lengua oral que, por su índole, carece de ella. Adaptar el español al quechua (escritura versus oralidad) habría conllevado que el Quijote fuese una historia más para escuchar que para leer.

Pudo haberse hecho una traducción más afín al canon literario, a través de la forma que mantiene el consabido tono neutro de toda carátula de libro. Por ejemplo, en el inglés es común que después del título se

\footnotetext{
17 En la traducción al inglés de John Ormsby (Proyecto Gutenberg), el término don permanece intacto, no obstante que la dicción de un angloparlante la pronuncia dan.

18 La dicción trivocálica de los monolingües quechuas es un hecho incuestionable. La escritura de términos castellanos a partir de la pronunciación del monolingüe quechua es contenciosa. Al fomentar esta escritura, los letrados bilingües no solo se autoexcluyen siendo parte del proceso de evolución lingüística, fingen una representación de su lengua como de algo ajeno, que no los alcanza. El quechua no solo es hablado por los monolingües; una escritura más próxima a la realidad de dicciones en contacto, de interacción idiomática, es lo más plausible.

19 Con esta práctica tan recurrente como la proliferación de neologismos se invade la soberanía de la lengua de coexistencia (el español) y, sobre todo, se prefija un método antipedagógico. Un niño monolingüe, que debe aprender el español para sobrevivir, no podrá corregir jamás su pronunciación de kawallu o dun, y será, como lo fueron sus padres, blanco de burlas y escarnios en la escuela y en la sociedad predominantemente castellana. Lo mejor sería tender a pronunciar y transcribir tal cual son las palabras de la otra lengua.
} 
refiera la autoría bajo la modalidad: written by / escrito por. Esta forma es plausible en el quechua, y así el título general de la obra de Cervantes, legible para los quechuahablantes, habría sido: Manchamanta Yachaysapa Wiraqocha Don Quixote. Miguel de Cervantes Saavedraq qilqasqan / El ingenioso hidalgo don Quixote de La Mancha. Escrito por Miguel de Cervantes Saavedra ${ }^{20}$, que se aproxima más al original que dice: compuesto por Miguel de Cervantes Saavedra.

\section{De los prados de La Mancha a la pampa de La Angostura}

La prolija traducción de los segmentos de la portada interior del libro — dedicatoria y privilegio real — es inevitablemente intrincada. Afortunadamente, en la llamada falsa carátula se halla el facsímil de la portada de 1605, que facilita la tarea de cotejar el original y la traducción de dichas secciones. La dedicatoria: Dirigido al duque de Béjar es Duque de Bejarpah Kamarispa.

No encontramos en la memoria ni en los diccionarios la construcción gramatical kamarispa, que equivaldría a la locución «dirigido a», pero es posible reconocer la raíz del verbo: kamay que es equivalente a «crear, formar, modelar, plasmar» ${ }^{21}$. El diccionario de la Academia Quechua de Cusco registra kamariy como sinónimo de kamay y equivalente a paqarichiy, kamay/crear y a musikay equivalente a «planificar, proyectar, idear, bosquejar» (1995, pp. 197 y 339). Asimismo, este diccionario da cuenta de que en la variante de Ayacucho kamay equivale, además, a «ley, mandato, obligación; talento, habilidad» (p. 197). La suma de estas acepciones podría aproximarse a la expresión dirigido a. Sin embargo, la presencia del morfema bilabial simple $p$ (kamarispa) desconcierta, pues la declinación -spa denota un gerundio (creando, plasmando, mandando), que, acaso, sea el resultado de un error de digitación. Lo más plausible habría sido la forma kamasqa o kamarisqa, con el posvelar simple $q$ que equivale a «creado, mandado; conferido» ${ }^{22}$.

20 Otro elemento que confluye en el conflicto oralidad/escritura es la naturaleza colectiva y anónima de los productos verbales orales que no tiene autor individual; los relatos no pertenecen ni siquiera al que los narra, sino a las colectividades. Una obra literaria (el Quijote) tiene un autor manifiesto (Cervantes).

21 Con este significado lo registran el diccionario de Domingo de Santo Tomás ([1561] 2006, p. 209), González Holguín ([1608] 2006, p. 209), Jorge Lira (2008, p. 174) y el de la Academia de la Lengua Quechua de Cusco (1995, p. 197). En su ensayo Camac, camay, camasca y otros ensayos sobre Huarochirí y Yauyos (2000), el estudioso francés Gerald Taylor amplía el campo semántico de esta locución. En el capítulo 1 (segmento «Las estrategias misioneras: resemantización») de nuestra tesis doctoral (2013), incidimos en la manipulación de este término durante el proceso de evangelización en los Andes.

22 El sufijo -sqa cumple muchas funciones. Insertado en un verbo, genera un participio pasivo que puede funcionar como adjetivo. Es el caso del verbo kamay/crear que deviene en kamasqa/creado. Esta forma, a su vez, puede conjugarse con posesivos: kamasqay/lo creado por mí, Diospa kamasqan/lo creado por Dios (Gonzales, 2010). 
El recurrente uso que el profesor Túpac Yupanqui le prodiga al morfema $h$ en lugar de $q$-por ejemplo: duque de Bejarpa $h^{23}$ — obedece a una actitud personal para marcar el territorio de la diferencia con quienes promueven la normatización. Después de décadas de desavenencias, cuando se llegó a un mínimo consenso, en el que se optó por una escritura estándar para la variante cusqueña, Yupanqui se alza como la voz disonante y persiste escribiendo a su manera ${ }^{24}$.

Hay que decir que en esta sección se avista una errata peculiar: a pesar de que en la carátula facsímil — que acompaña a la transcripción quechua - se alude al duque de Béjar como «Conde de Barcelona y Bañares», en la versión traducida se lee: «Conde de Benalcaçar y Pañares». Después de cotejar las portadas originales, constatamos que la edición de 1605 tiene al menos dos portadas: en una dice «Conde de Benalcaçar y Bañares» $y$ en la otra, «Conde de Barcelona y Bañares» ${ }^{25}$.

\section{La jerga real}

La tasa, el testimonio de las erratas, la dedicatoria formal, la autorización real y el prólogo son una maraña infranqueable ${ }^{26}$. Estas secciones, que preceden a la novela, denotan una predilección desmedida por la invención de neologismos; racimos de términos castellanos que, al no tener equivalentes en quechua, son mantenidas arropadas por el traductor con declinaciones quechuas:

Llapanpiqa 83 pliegon rixurin, chaymi tukuy liwruqa 290 maravidí balirun; chaymi kay lisinsha kamarikun chay baliypi bindikunanpah, kay prishutahmi churakunan qilqah qallariyninpi... (p. 10) [el subrayado es nuestro].

En total tiene 83 pliegos, que al dicho precio monta el dicho libro doscientos y noventa maravedís y medio, en que se ha de vender en papel; y dieron licencia para que a este precio se pueda vender, y mandaron que esta tasa se ponga al principio del dicho libro... ${ }^{27}$.

23 En la escritura normatizada del quechua sureño, promulgada por el Ministerio de Educación del Perú en 1987, sería «Bejarpaq/para Béjar».

24 Un caso excepcional de una «escritura personal» es el del poeta cusqueño Kilku Warak'a (Andrés Alencastre), que optó por el uso de la consonante c en lugar de $c h$. Su espléndida poesía enriqueció el lenguaje quechua del siglo XX. Por lo demás, los poetas son los únicos que pueden tomarse estas licencias (Taki parwa, 1999).

25 Bañares aparece en la versión quechua como Pañares.

26 La sección «Versos preliminares» no colisiona tanto en el conflicto oralidad/escritura. La poesía, desde siempre, está más vinculada a lo oral; no ha dejado de ser un canto. Para nuestro gusto, el soneto «Urganda, la desconocida» discurre más suelto y sonoro en quechua que en el original castellano.

27 Don Quijote de la Mancha, p. 3. 
El sutil vocativo desocupado lector es vertido con la confección de un neologismo baladí: "Qasisqa qilqa t'ahwih»" ${ }^{28}$, que no es propiamente un entramado verbal sino una superposición de términos remotamente vinculantes.

\section{En un lugar de La Mancha}

El fraseo del memorable inicio de la novela de Cervantes discurre con contención y fluidez:

Huh k'iti, La Mancha llahta sutiyu pin, mana yuyarina markapi, yaqa kay watakuna kama, huh axllasqa wiraqucha, t'uhsinantin «hidalgo», ch'arki rocín kawalluchayuh, phawakachah alquchayuh ima tiyakuran...

En un lugar de La Mancha, de cuyo nombre no quiero acordarme, no ha mucho tiempo que vivía un hidalgo de los de lanza en astillero, adarga antigua, rocín flaco y galgo corredor...

La fidelidad del pasaje es plausible, aunque el segmento «de cuyo nombre no quiero acordarme» conlleva una ligera incongruencia. Yupanqui la vierte «mana yuyarina markapi», equivalente —más o menos-a un lugar «no digno de recordación», o un lugar «no recordable», que altera el manifiesto propósito del narrador (versión original) que no tiene la intención de agraviar aquel recóndito lugar de La Mancha, sino mantenerlo en reserva, pues aunque lo recuerde no quiere evocarlo, registrarlo29. Así la versión quechua nos priva de la regalada gana del narrador de no querer acordarse de un nombre.

La frase retórica lanza en astillero es inviable en el runasimi; (acaso) por eso se disipa, no aparece en la traducción. En cambio, el término hidalgo (trocado por wiraqucha en la carátula) se mantiene tal cual. A este sustantivo (hidalgo) y a otros términos el traductor los vierte entrecomillados, una marca gramatical de la escritura ajena al quechua ${ }^{30}$. En este segmento en el que excepcionalmente el narrador se alude a sí mismo, su declaración personal es desestimada por el traductor que mantiene el párrafo en tercera persona. Así la construcción impersonal mana yuyarina reemplaza a la muy personal revelación «no quiero acordarme». El traductor no entreteje el vínculo entre el narrador interno y externo de la versión castellana.

28 T'ahwih [t'aqwiq] es la forma sustantivada del verbo t'aqwiy: «rebuscar, hurgar, escudriñar». 29 La versión de Ormsby acata el designio del narrador: «ln a village of La Mancha, the name of which I have no desire to call to mind» $(2011$, p. 48)

30 La naturaleza oral del quechua no admite los signos de interrogación, admiración o las comillas aun en texto escrito. En runasimi la forma interrogativa no está determinada por el tono de voz, sino por una marca concreta, el sufijo -chu; de modo que los signos de interrogación, en un texto escrito quechua, son prescindibles. 


\section{Sobrina, nieta y ama}

En el capítulo VII, que le sigue al nefasto escrutinio y quema de libros de caballería cuya lectura habría inducido al Quijote a la locura, Túpac Yupanqui confunde a la sobrina con la «nieta» del Quijote, lo que supone que el Caballero de la Triste Figura tuvo una hija o un hijo. Asimismo, confunde al ama de llaves con la supuesta nieta del Quijote. Como se sabe, en los parlamentos de este capítulo intervienen el barbero, el cura, la ama y la sobrina de don Quijote. He aquí la versión de Yupanqui:

Mit'ani warmiqa hahiy tutayá, llapa liwrukunata uywa kanchapi, raqay raqay sunqunpi kanarapusqa.

Aquella noche quemó y abrasó el ama cuantos libros había, en el corral.

-Manan supaychu —nispayá rimarin Quijoteh waqinpa ususinqa.

—No era diablo — replicó la sobrina [la hija del hermano de Quijote].

-Manan yachanichu Frestonchus icha Fritonchus sutin chaytaga. Ichaqa manan qunqanichu «tón» nisqapi sutinpa tukusqantaqa, nispan rimarin hawaychanqa.

—No sé —respondió el ama— si se llamaba «Frestón» o «Fritón», solo sé que acabó en tón su nombre (p. 56).

Por tanto, la sobrina [waqinpa ususin] deviene en hawaycha («nietecita»), y «el ama» — que Yupanqui inicialmente traduce «mit'ani warmi»deviene también, líneas abajo, en hawaycha/nietecita. Más adelante ( $p$. 71), la confusión sobrina/nieta persiste.

\section{Lengua oral en labios de los letrados}

Al margen de sus aciertos y deslices, hay que destacar el arrojo y la tenacidad del profesor Yupanqui. Nadie acometió semejante aventura quijotesca. Arguedas se habría rehusado; su espléndida traducción del manuscrito de Huarochirí fue de la variante de Yauyos al español, quechuizando denodadamente el castellano; lo contrario equivale - como en el mito andino- - a arrear piedras a chicotazos, y Yupanqui lo intentó. Se supone que estos desprendimientos llevan la buena voluntad de preservar, difundir y revalorar el runasimi, pero la traducción precipitada no es el modo apropiado; con estas gestas se activa su extinción. El internet y los medios audiovisuales — como se auguraba al inicio— no lograron la disolución de las lenguas nativas, pero su último hálito puede disiparse en el seno de los propios letrados difusores o custodios del idioma, que arremeten de manera directa contra ella ${ }^{31}$. No es imposible, desde luego, 
traducir una obra literaria o un texto contemporáneo al quechua, pero es un ejercicio laborioso que no se puede cumplir apresuradamente ${ }^{32}$. Para lograrlo hay que deconstruir, descomponer la retórica, los conceptos y abstracciones con que se ensambla una obra literaria hasta llegar a sus formas simples, básicas, llanas y concretas, que constituyen la índole del runasimi ${ }^{33}$.

Me hubiera gustado leerlo totalmente y con delectación en mi lengua materna, y colocarlo en la lista de lecturas obligatorias de mis cursos, pero al cabo de sinfín de intentos siento que me es fatigante, arduo y, por momentos, inaprensible. He leído unos cuantos capítulos con auxilio de la versión castellana; y no puedo ocultar mi inquietud: ¿Quiénes leerán el Quijote en quechua? ¿Los académicos quechuahablantes? ¿Un comunero bilingüe de Paqchanta? Hay que mencionar finalmente que la versión quechua pretende una autosuficiente insólita al prescindir de notas aclarativas $^{34}$. En la primera parte del Quijote hay apenas tres Ilamadas al pie de página, escritas naturalmente en español: en el capítulo VII, p. 58, sobre la serpiente amazónica shushupe; en el capítulo VIII, p. 64, referida a la madera roble; y en el capítulo IX, p. 70, referida a la fruta conocida en Perú como granadilla.

¿Subestimó Yupanqui al lector quechuahablante?. Las versiones en inglés contienen centenares de notas, lo mismo que las ediciones en español; puntuales acotaciones que aclaran o encaminan al lector sobre una

comenzará con la versión quechua de las obras de Vargas Llosa y García Márquez. «Con estas publicaciones en lenguas originarias se da mayor conocimiento a Cusco y a los hablantes... [y las traducciones de los dos Nobel] «le darán un valor simbólico al quechua, y los hablantes dejarán de tener vergüenza de expresarse en este idioma», señala un funcionario (diario La República, edición del 29 de agosto de 2015, sección «Ocio y Cultura»). Apenas concluida la lectura de la noticia, ya nos turba el desasosiego: ¿cómo urdirán los traductores la construcción abstracta «Clásicos de la literatura latinoamericana» o Cien años de soledad? 32 En el periódico español $A B C$ (30 de junio 2015), Yupanqui señala que la primera parte fue traducida en dos años, y la segunda parte en otros dos años, y que lo hizo a pedido de Miguel de la Quadra-Salcedo, reportero español, promotor de la ruta Quetzal. «Un día llegó Miguel y, con su acento vasco, me dijo que venía para que le tradujera Don Quijote porque en varias partes como Argentina y Cusco le dijeron que yo era la persona que mejor lo podía traducir. Me sorprendió, pero le dije que lo haría con la dedicación que merecía la tarea». Recuperado de http://www.abc.es/cultura/libros/20150627/abci-traducen-segunda-partequijote-201506262024.html

33 En 2012, tradujimos el manifiesto del movimiento Occupy Wall Street (OWS) con mis estudiantes del nivel Intermediate II de New York University. Usando el español como lengua filtro, trabajamos durante un semestre desmontando las abstracciones y términos retóricos hasta llegar a las acciones concretas, con las que configuramos un texto breve del siglo XXI en una lengua ancestral. La versión final se halla en el portal de OWS. Recuperado de http:// translation.nycga.net/languages/quechua

34 La estudiosa peruana Lydia Fossa señala: «No existe una traducción transparente: toda traducción debe dar cuenta del filtro que ella constituye y de las adaptaciones y distorsiones que ella conlleva. Si este hecho se escamotea, se entra en el campo de la doblez y el disimulo (2006, p. 500). 
situación dudosa, un lugar desconocido, una palabra arcaica, un giro idiomático, un localismo, etc.

En 2006, cuando escribía un artículo sobre la traducción de Yupanqui $^{35}$, viajé a Cusco y, para salir de dudas, leí algunos párrafos de la versión quechua a monolingües y bilingües. Mi compadre Pancho Atawpuma, gran narrador monolingüe de la comunidad de Aqchawata, Calca, al cabo de tres o cuatro intentos me increpó: «Mejor te cuento del condenado del abra de Amparaes» ${ }^{36}$.

35 El artículo «De los prados de la Mancha a los páramos andinos. El Quijote en quechua» sobre la traducción de la primera parte del Quijote — base de este texto— salió en 2007 en la Primera Revista Latinoamericana de Libros, 1, pp. 20-23.

36 «Aswan willasayki Amparaes abra condenadomanta». 


\section{REFERENCIAS BIBLIOGRÁFICAS}

Academia Mayor de la Lengua Quechua. (1995). Diccionario quechua-español-quechua. Cusco: Ediciones de la Municipalidad.

Arguedas, J. M. (1984). Katatay. Lima: Horizonte.

dad de Lima.

(1986). Cantos y cuentos quechuas II. Lima: Municipali-

Cervantes Saavedra, M. ([1885] 2011). Don Quixote. The Project Gutenberg. Recuperado de www.jus.uio.no/sisu/don_quixote.miguel_de_cervantes/ portrait.a4.pdf

(2004). Don Quijote de la Mancha. Madrid: Real Academia Española, Asociación de Academias de la Lengua Española.

Fossa, L. (2006). Narrativas problemáticas. Los inkas bajo la pluma española. Lima: Instituto de Estudios Peruanos y Fondo Editorial de la Pontificia Universidad Católica del Perú.

Gonzales, O. (2010). Runasimi. Lengua y cultura. Intermediate, I-II, vol. II. Nueva York York: Center for Latin American and Caribbean Studies CLACSNYU.

(2013). El condenado: peregrinaje y expiación entre dos mundos. Voz y memoria quechua en la configuración de la novela Los ríos profundos. Lima: Facultad de Letras y Ciencias Humanas de la Universidad Nacional Mayor de San Marcos.

(2014). Elegía Apu Inka Atawallpaman. Primer documento de la resistencia Inka (siglo XVI). Lima: Pakarina Ediciones.

Lira, J. A. (1990). Cuentos del Alto Urubamba. Cusco: Centro Bartolomé de Las Casas.

dad Ricardo Palma.

(2008). Diccionario quechua-castellano. Lima: Universi-

Payne, J. (1984). Cuentos cusqueños. Cusco: Centro Bartolomé de Las Casas.

Tomas, Domingo Santo (2006). Lexicón o Vocabulario de la lengua general del Perú. Lima: Ediciones el Santo Oficio.

Taylor, G. (2000) Camac, camay, y camasca y otros ensayos sobre Huarochiri y Yauyos. Lima: Instituto Francés de Estudios Andinos.

Warak'a, Kilku (1999). Taki parwa/22 poemas de Kilku Warak'a. Cusco: Navarrete y Biblioteca Municipal de Cusco. 